\title{
ESTABLISHING A COMBINED FORECASTING MODEL: A CASE STUDY ON THE LOGISTIC DEMAND OF NANJING'S GREEN TEA INDUSTRY IN CHINA
}

\author{
Hung-Lung LIN ${ }^{1 *}$, Chin-Tsai LIN ${ }^{2} 2$ \\ ${ }^{1}$ School of Economics and Management, Sanming University, No. 25, \\ Ching-Tung Rd., Sanming City, Fujian Province, China \\ ${ }^{2}$ Department of Business Administration, Ming Chuan University, \\ No. 250 Zhong Shan N. Rd., Sec. 5, Taipei 111, Taiwan
}

Received 24 February 2020; accepted 11 October 2020

\begin{abstract}
The sales logistics of tea leaves is a process that organically integrates basic logistics activities, including transportation, storage, loading, unloading, carrying, packaging, distribution processing, delivery, and information processing. This process requires quick and accurate forecasting of the logistics demand in the green tea market and the provision of feedback to businesses and farming partners, revealing the need for a simple and accurate forecasting method. Responding to and solving the unclear information and limited data available regarding the green tea market are critical. Therefore, this study established a simple, quick, and accurate model through the use of time series and the technique for ordering preferences by similarity to the ideal solution. Finally, the actual logistics demand in the Nanjing green tea industry was employed to verify the proposed model's practicality and feasibility, which may provide a critical reference for relevant parties such as businesses and researchers.
\end{abstract}

Keywords: logistics demand, logistics demand forecast, green tea industry, time series forecast model, technique for ordering preferences by similarity to the ideal solution (TOPSIS).

JEL Classification: D49, L66, L11, C52, C53, D70.

\section{Introduction}

\section{Background}

In recent years, demand has been increasing in the global tea market. In particular, the consumption of green tea in the Asia-Pacific has been increasing at a greater rate than anywhere else. According to National Bureau of Statistics of China (NBSC) in 2018, the quantity of tea exported from China each year has remained between 300,000 and 360,000 metric tons from 2013 to 2018 (NBSC, 2018). Specifically, China's tea export in 2016 was 329,200 metric

*Corresponding author. E-mail: hsa8936.hsa8936@msa.hinet.net

Copyright $\odot 2020$ The Author(s). Published by Vilnius Gediminas Technical University

This is an Open Access article distributed under the terms of the Creative Commons Attribution License (http://creativecommons. org/licenses/by/4.0/), which permits unrestricted use, distribution, and reproduction in any medium, provided the original author and source are credited. 
tons at US $\$ 1,490,000,000$; in 2017 , it increased to 355,300 metric tons for US $\$ 1,609,000,000$, which increased by $8.25 \%$ and $8.4 \%$, respectively. In 2018 , China's tea export reached 364,700 metric tons at US $\$ 1,777,000,000$, which increased by $1.68 \%$ and $7.21 \%$, respectively (National Bureau of Statistics of China, 2018). These values indicate that Chinese tea represents a promising prospect in the global market. In addition, as Chinese tea culture and health preserving culture have gradually embedded themselves in the minds of Chinese and foreign consumers, a base consumer group has been established, and the global market for tea consumption has gradually stabilized. With technological improvements in the Chinese tea industry and the increase of exports to the emerging market, demand has been steadily increasing, which shows that Chinese tea exports are a critical indicator of economic growth in both the global and domestic markets.

Tea industry is one of the oldest agro-based well-organized industries. The main connection of the agriculture industry and logistic industry is the sales logistics of agricultural products, which describes the physical transportation of products from the supply location of a farmer or a production company to the delivery location (Gao et al., 2018). Agricultural products sales logistics organically integrate basic logistic activities such as transportation, storage, loading, carrying, packaging, distribution processing, delivery, and information processing, based on the characteristics of the agricultural products and actual demand (Jiani \& Hans-Dietrich, 2018; Lamsal et al., 2016; Liu et al., 2019). Nanjing is one of the distribution centers of famous and quality teas in the country, facilitating transportation of goods to surrounding areas. As a provincial-level capital, Nanjing has a well-developed logistic industry and is well connected with foreign markets. Therefore, the green tea industry in Nanjing is greatly superior, in terms of transportation and market size, to other cities in the country. The geographical location of Nanjing established its logistic advantages in green tea sales. Green tea companies obtain fresh tea leaves from their own plantations or from individual farmers to process. The processed tea is then packaged according to the market requirements. Finally, the products are transported to teahouses, specialty stores, tearooms, or department store counters through their own transportation division or a third-party transportation company for sales.

The outstanding development of Nanjing's logistics industry has improved the accessibility of sales channels for green tea in Nanjing. Collaborations among green tea companies and other logistic companies mitigate various unnecessary links in the circulation of green tea and reduce costs. Moreover, the logistics company can request orders from the collaborating green tea companies according to retailers' feedback to prevent tea companies from blindly producing and buying raw materials. However, the collaboration still falls short in certain aspects of the green tea industry's development. For instance, factors such as the wide geographical dispersion of tea farmers in the Nanjing country side, incomplete data for regional production and sales, and computer information technology factors have limited immediate understanding and sharing of industry information, caused untimely logistics demands forecasts by the green tea industry, and created gaps in agricultural logistic information between townships. Such problems render tea farmers unable to meet market demand, and the production and logistics of tea leaves are carried out blindly. In addition, an inability to quickly and precisely forecast logistic demands in the green tea market and provide feedback 
to collaborating companies and farmers causes unnecessary loss for the green tea industry of Nanjing. Therefore, quickly and precisely forecasting the logistic demands of Nanjing's green tea market to reduce circulation cost, increase profit, and further promote the development of the green tea industry is a crucial concern for all companies in the green tea industry.

\section{Literature study}

Studies have employed various forecasting models for forecasts and applications in fields including logistics. For example, Ji et al. (2015) used artificial neural network (ANN) to forecast the port logistics demand and propose a reference for the port planning and decision. Baginski and Hassell (1997) used regression analysis (RA) to predict transportation mean. Zhang et al. (2013) combined the grey forecast and logistic growth curve model to improve the accuracy of forecast model of cargo throughput for the port. Since Bates and Granger (1969) first proposed the idea of combining forecasts in the 1960s, studies on the methodology and application of the forecast combination approach have rapidly developed. Such as Lin et al. (2019) used exponential smoothing (ES) and the technique for order preference by similarity to ideal solution (TOPSIS) to solved excess warehouse storage in the e-business based plant shops for Chinese plant industrial. Colino et al. (2012) combined ARMA and VAR model to evaluate US agricultural futures markets, the results shows the proposal model can improved the accuracy of price forecasts. Fernández-Vázquez and Moreno (2017) proposed a model to combine entropy and regression, and used simulation exercise and a real-world example that aims at predicting gross regional product growth rates for a regional economy.

Additionally, studies have criticized traditional regression models and time-series models by stating that-considering the linear structural relationship-a significant nonlinearly dependent relationship exists even if a linearly independent relationship is identified. Accordingly, the nonlinear characteristics in market changes cannot be accurately modeled. Therefore, nonlinear and combined models have been used for analyses and forecasts. Baffour et al. (2019) combined the model proposed by Glosten et al. (1993) with an ANN to forecast the exchange rates of five major international currencies. Guo et al. (2020) adopted nonlinear and multifractal methods to forecast the spot and futures prices in the Chinese copper market. Ghosh et al. (2019) proposed combining nonlinear dynamics, econometric models, and machine learning algorithms for time-series modeling and forecasting of the daily closing prices of four emerging Asian stock indices. Xu et al. (2019) developed an innovative method combining unrestricted mixed data sampling and support vector quantile regression to forecast and analyze Chinese stock market volatility. Zainuddin et al. (2019) used a timeseries forecasting model integrating bootstrap and double bootstrap ANNs for analyses and verification of actual data, namely Wolf's sunspot data, Canadian lynx data, and Malaysian ringgit/United States dollar exchange rate data. The aforementioned studies have all provided their own viewpoints and compared their proposed methods with traditional ones; the results have all revealed their methods to be more accurate and useful compared with the traditional methods. Each of these proposed forecasting models has its strengths and weaknesses. Generally, linear and nonlinear time-series forecasting models require 30 or more data points that present a trend and are regular. The time series requires data to have two or more peaks, present a single trend, and be regular and self-adjusting. A total of 50 or more data points are required for autoregressive integrated moving average (ARIMA) models. 
Since Deng's (1982) development of the grey model (GM), grey system theory has been widely applied in various fields. The strengths of the GM include the small number (four or more) of raw series data points required for modeling, the absence of a priori assumptions regarding the distribution of variable series before modeling, and simple model operations. Because the GM has a relatively short development history compared with other models, its applicability to different data types has not been clarified; it has only been known to make more accurate forecasts, compared with other models, when short-term and limited data are targeted. Accordingly, to compensate for the GM's weaknesses, scholars have developed modified GMs combining different theories and successfully verified their accuracy. For example, Jia et al. (2020) combined a GM with a Markov chain to forecast the amount of coal consumption in Gansu, China. Carmona-Benítez and Nieto (2020) discussed passenger demand for different air transport routes with consideration of the seasonal changes in demand and proposed the damp trend GM, which exhibited higher accuracy compared with the conventional GM. Hu (2020) combined a GM with an ANN to predict the demand of the electronics manufacturing industry for magnesium. Wang et al. (2018) forecasted and analyzed the US monthly production of shale gas by combining a GM with ARIMA, the accuracy and practicality of which were verified by their research results. Many other GMbased models have been verified and applied in various fields, such as the Grey Bernoulli, Grey Fourier, GM (1, N), and GM $(2,1)$ models (Zill \& Cullen, 2000; Chang et al., 2005; Hsu, 2003; Hsu \& Chen, 2003; Wu et al., 2019); such models are not addressed in the present study given the limited space here.

Overall, studies have employed a GM-for the establishment of linear or nonlinear forecasting models or because of the unclear or limited data available-and combined it with various methods to mitigate and compensate for the weaknesses of the stand-alone GM. However, some weaknesses have remained in these modified models, regarding which the present study proposed three viewpoints: (1) Limitations in the theories, methods, and data collection: Against a background of big data, a larger amount of data indicates more choices of models and methods, more choices and higher accuracy of models under the assumptions of different theories and methods, and thus less distorted forecasts. However, because the amount of data for emerging markets, such as the studied industry and many others, remains insufficient, choosing a simple, quick, accurate, and theory-based method is particularly crucial for these industries. (2) Problems of complex model theories and calculation: Studies have all verified their proposed combined models to be more accurate than traditional stand-alone models. However, the mathematical basis of combined models is complex, and the difficult simulation and computation involved cannot be operated or executed easily even if computers are used. This makes the application and operation of such models challenging for managers of an average business in forecasts. (3) Selection of time points: Each of the combined models has been compared with stand-alone models in terms of the accuracy of forecasts, but no research has investigated the accuracy of models in relation to different time points. For example, a scenario where models A and B outperform each other in terms of accuracy in the first and second halves of a period, respectively, will lead to questions as to which of the two is the more suitable option and how the choice will 
change in short-, mid-, and long-term trend analyses. These have been the main questions facing this research.

In response to the aforementioned questions, this study constructed a combined forecasting model that facilitates simple, quick, and accurate calculation and then determined and verified its applicability and accuracy. The following detailed solutions were proposed by the present study: (1) Choosing forecasting models with a simple theoretical basis and calculation: This study, considering the theoretical foundation and limited data available, chose the ES, RA, and GM $(1,1)$ models as the basis for establishing stand-alone models. (2) Constructing a combined forecasting model: The value of combined forecasting models regarding their accuracy has been verified by various studies (Lin et al., 2019; Colino et al., 2012; Jia et al., 2020; Carmona-Benítez \& Nieto, 2020; Hu, 2020; Wang et al., 2018). The present study established a combined forecasting model on the basis of TOPSIS, which is an effective method involving simple calculation for multicriteria decision making. Because it does not require complex questionnaire surveys in the preliminary research phase and involves a simple calculation process, TOPSIS has been widely applied in various fields (Lin \& Cho, 2020). TOPSIS, unlike other methods such as the analytic hierarchy process and ELimination Et Choice Translating REality (ELECTRE), considers the risks involved in each optimal solution, namely using the basic concepts of the ideal and negative ideal solutions. The ideal solution refers to the optimal solution under a given assumption, and the ideal solution's attribute values result in the optimal values of all plans, whereas the negative ideal solution leads to the opposite. The rule of plan ordering involves comparing each plan with the ideal and negative ideal solutions. The plan that is the closest to the ideal solution and also far from the negative ideal solution (risk) is determined to be the best plan of all candidate plans (Lin \& Cho, 2020). (3) Verifying the accuracy and practicality of the combined forecasting model: Considering the time points and based on the concept of comprehensive weight in TOPSIS, this study determined the objective value of forecast errors in each time point to solve the problem of model accuracy varying in different time periods. Finally, the proposed model's levels of accuracy at different time points were compared and verified.

\section{Novelty and purpose}

The sales logistics of tea leaves is a process that-according to the characteristics of and actual demand for the flow of tea leaves-organically integrates basic logistics activities, including transportation, storage, loading, unloading, carrying, packaging, distribution processing, delivery, and information processing. The process requires quick and accurate forecasting of logistics demand in the green tea market as well as the provision of feedback to business and farming partners, indicating the need for a simple and accurate forecasting method. Given the importance of an appropriate response and solutions to the unclear information and insufficient data available regarding the logistics demand, this study used time series and a TOPSIS model to establish a simple, quick, and accurate combined forecasting model. Subsequently, the forecasting computation of logistics demand in the Nanjing green tea industry was employed as a case study to verify the practicality and feasibility of the proposed model, which could provide a critical reference to relevant parties such as businesses and researchers. 


\section{Modeling}

The modeling of this study required three stages. The first stage was establishing single forecasting models and explaining the basis of the ES model, RA model, and grey model. The second stage was establishing a combined forecasting model by applying the TOPSIS model on the absolute error of each model established in the first stage. The third stage was forecasting the logistic demand trend of the green tea industry over 10 years using the established combined forecasting model and proposing specific suggestions and countermeasures, based on the analysis results, for companies and scholars' analysis of green tea market demands. The modeling process was as presented in Section 2 to 3 and the specific research framework as presented in Figure 1.

\section{Establishment of single forecasting models}

The ES, RA, and GM models were used in this study as the time-series models. The equations of the ES and RA models, considering their common adoption by researchers, are not included in the main text; for information regarding this matter, please refer to the Appendix.

\subsection{Forecasting based on the ES model}

Step 1: Determining the theoretical value of the model

According to the forecast results obtained using the ES times calculation model.

Step 2: Determining the absolute error of the model

The aforementioned smoothing equation was used to obtain the theoretical value of the forecast. The difference between the theoretical value and the actual value was subsequently used to obtain the absolute error.

\subsection{Forecasting based on the RA model}

In the RA forecasting process, the forecasting object is set as the dependent variable, and the factors related to the forecasting object are set as the argument; with enough data on the argument, the analysis of correlation and causal analysis are used to obtain a regression equation, which is used for forecasting. Before analytic forecasts can be conducted using the correlation of each factor, the correlation between objects must be determined because the weaker the correlation is, the lower the forecasting precision is, and vice versa. In addition, the stability of the codependency between objects must be analyzed before the forecast is conducted using the regression model. If the codependency is stable or exhibits no notable changes during the forecasting period, the regression model established on the basis of old data may be considered successful.

Step 1: Dependent variables and arguments

The forecasting object is set as the dependent variable, and the factors related to the forecasting object are set as the argument; with enough data on the argument, the analysis of correlation and causal analysis are used to obtain a regression equation, which is used to 


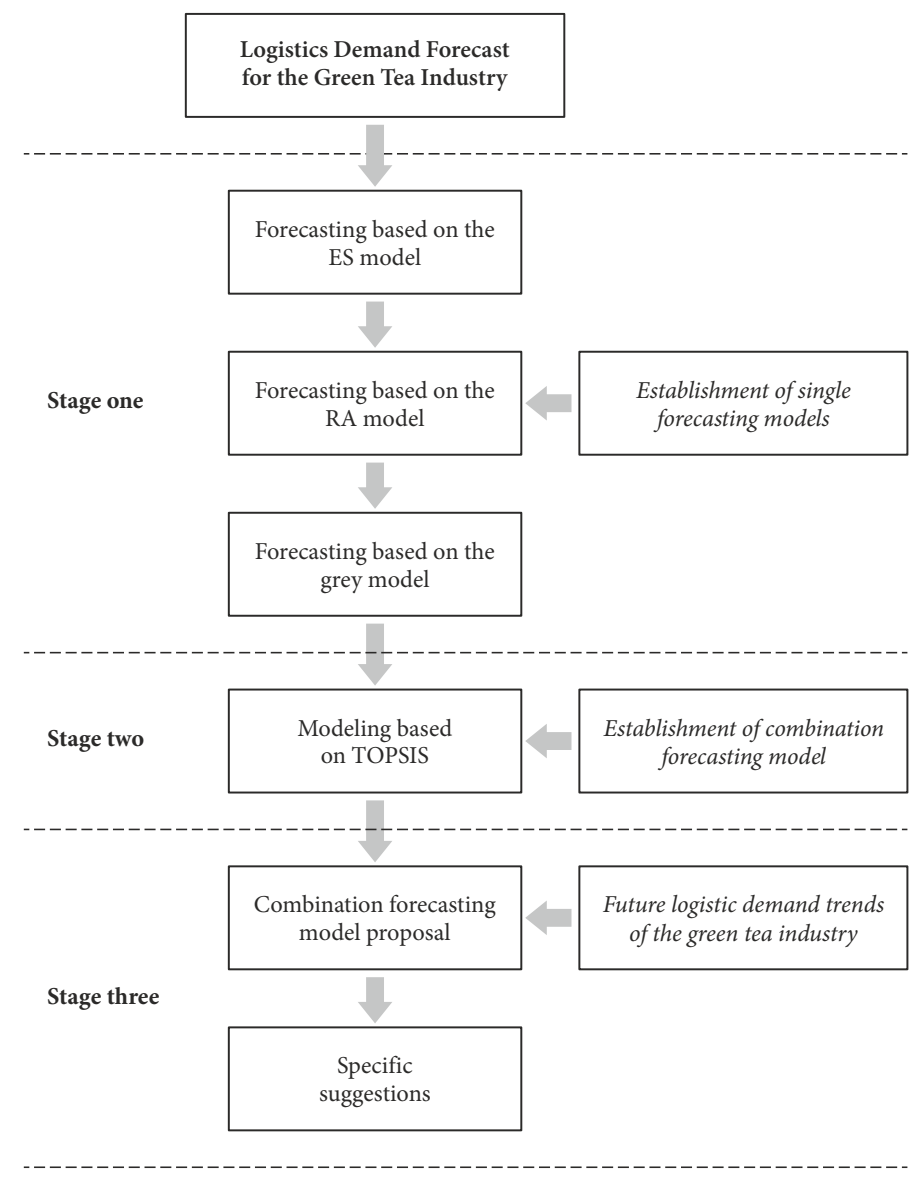

Figure 1. Research framework

conduct the forecasting, which is suitable for time sequences with no periodic changes (Hilary, 1967). In general, $Y$ is set as the dependent variable and $X$ as the argument, which is the influencing factor of the dependent variable $Y$.

Step 2: Determining the RA forecasting model

This study established the RA model according to the trend of changes revealed by the scatter plot of the research data. Therefore, the scattering types of the points determined the type of model established.

Step 3: Determining the theoretical value of the model

Once the model is determined, the theoretic forecasting value is obtained through calculation using its basic equation.

Step 4: Determining the absolute error of the model

According to the value obtained in step three, the absolute error was obtained using Eq. (A4). 


\subsection{Forecasting with the grey model}

The grey model is a forecasting technique used to obtain forecasts on systems with uncertain factors. By analyzing the different level of development trends for each factor, that is, identifying the pattern of changes in the system through processing of initial data using analysis of correlation, the grey model establishes a regulated data sequence, which is used to establish a different differential equation model to forecast the eigenvalue of a time period in the future (Bai \& Sarkis, 2018). Grey models can obtain forecasting results with higher precision using relatively less data for a forecast involving a short period. The basic GM $(1,1)$ model is as follows (Deng, 1982):

Step 1: Determining the initial time sequence

Establishing initial data sequence:

$$
X^{(0)}=\left\{x^{(0)}(1), x^{(0)}(2), \ldots, x^{(0)}(n)\right\} .
$$

Step 2: Determining the accumulative generation sequence

Generating a new sequence through accumulation:

$$
X^{(1)}=\left\{x^{(1)}(1), x^{(1)}(2), \ldots, x^{(1)}(n)\right\} .
$$

Then, the corresponding differential equation of the $\operatorname{GM}(1,1)$ model is

$$
\frac{d x^{(1)}}{d t}=\alpha X^{(1)}+\mu \text {. }
$$

where $\alpha$ is the development grey number and $\mu$ the endogenous control grey number.

Step 3: Calculating the parameter vector $\hat{\alpha}$ to be estimated Set $\hat{\alpha}$ as the parameter vector to be estimated; $\hat{\alpha}=\left(\frac{a}{b}\right)$ can be solved using the least
squares method:

$$
\alpha=\left(B^{T} B\right)^{-1} Y_{n} .
$$

Step 4: Determining the theoretical value of the model

The forecasting model is obtained by solving the differential equation

$$
\hat{X}^{(1)}(k+1)=\left[X^{(0)}(1)-\frac{b}{a}\right] e^{-k t}+\frac{b}{a}, k=0,1, \ldots, n .
$$

The theoretical forecasting value of the model is obtained using Eq. (14).

Step 5: Determining the absolute error of the model

After the theoretical forecasting value of the model is determined by step four, Eq. (A4) is used to obtain the absolute error.

\section{Establishment of the combined forecasting model}

Multi-property decision-making primarily involves calculating an optimal plan through evaluating the relative importance of the properties (Zhuang et al., 2019; Zemlickiené \& Turskis, 2020; Chao \& Peng, 2020; Mahmoudi et al., 2020). This method is appropriate for a 
limited number of plan options that are typically discrete and already known. According to the problem's properties, decision-making methods can be divided into subjective and objective ones. In TOPSIS, proposed by Hwang and Yoon (1981), the decision-maker determines a positive ideal solution and a negative ideal solution. The distance between the evaluated plan and the positive ideal solution is then calculated. The advantage of this method is that it enables the priorities of the evaluated plans to be determined according to their relative distance from the ideal solution, thereby avoiding the problem of incomparability between plans that are either equally close to the positive ideal solution or distant from the negative ideal solution (Zhuang et al., 2019; Zemlickienè \& Turskis, 2020; Chao \& Peng, 2020). Based on the forecasting results obtained with the triple ES method, the RA method, and the grey model, this study calculated the absolute error for each model and the mean absolute error for each model within the forecasting period. Subsequently, the dimensionless quantity of the mean absolute error for each model was obtained. Finally, the TOPSIS was applied to obtain the weight, providing the ultimate forecasting results. Relevant equations follow (Lin \& Cho, 2019; Lin et al., 2020).

Step 1: Determining the decision matrix

The decision matrix $D$ was established based on the absolute error for each single forecasting model:

$$
D=\left[\begin{array}{cccccc}
X_{11} & X_{12} & \cdots & \cdots & X_{1 j} & X_{1 n} \\
X_{21} & X_{22} & \cdots & \cdots & X_{2 j} & X_{2 n} \\
\vdots & \vdots & \cdots & \vdots & \vdots & \vdots \\
X_{i 1} & X_{i 2} & \vdots & \vdots & X_{i j} & X_{i n} \\
\vdots & \vdots & \cdots & \vdots & \vdots & \vdots \\
X_{m 1} & X_{m 2} & \cdots & \cdots & X_{m j} & X_{m n}
\end{array}\right],
$$

where $i=1,2, \ldots, m, j=1,2, \ldots, n$.

Step 2: Determining the standardized decision matrix

Data of the absolute error for each model were standardized using the following equation.

$$
r_{i j}=\frac{X_{i j}}{\sqrt{\sum_{j=1}^{n} X_{i j}^{2}}}, i=1,2, \ldots, m, j=1,2, \ldots, n .
$$

Step 3: Determining the ideal point and negative ideal point

The following equations were used to obtain the ideal point and negative ideal point of the standardized data for each year:

$$
\begin{aligned}
& V_{k}^{+}=\operatorname{Max}\left(r_{i j}\right) ; \\
& V_{k}^{-}=\operatorname{Min}\left(r_{i j}\right),
\end{aligned}
$$

Step 4: Determining the positive and negative ideal Euclidean distance

The following equations were used to solve for the ideal Euclidean distance and negative ideal Euclidean distance for each model.

$$
S_{i}^{+}=\sqrt{\sum_{j=1}^{n}\left(V_{i j}-V_{j}^{+}\right)^{2}}, i=1,2, \ldots m ;
$$




$$
S_{i}^{-}=\sqrt{\sum_{j=1}^{n}\left(V_{i j}-V_{j}^{-}\right)^{2}}, i=1,2, \ldots ., m .
$$

Step 5: Determining the similarity and weight

The following equation was used to calculate the similarity of each model:

$$
C_{i}^{*}=\frac{S_{i}^{-}}{S_{i}^{*}+S_{i}^{-}}, i=1,2, \ldots ., m .
$$

The following equation was used to normalize the similarity of each model to obtain the weight of each single forecasting model:

$$
W_{i}=\frac{C_{i}^{*}}{\sum_{i}^{n} C_{i}^{*}}, i=1,2, \ldots, n .
$$

Step 6: Determining the combined forecasting model

The combined forecasting model was established through the weights obtained in the previous step.

$$
Y=W_{1} Y_{1}+W_{2} Y_{2}+W_{3} Y_{3}
$$

where $Y$ is the forecasting value obtained from the combined model, $Y_{1}$ is the value obtained from the ES, $Y_{2}$ is the value obtained from the exponential regression model, and $Y_{3}$ is the value obtained from the grey model.

Step 7: Error verification on the combined forecasting model

The theoretical value for the combined forecasting model is compared with the theoretical value for each stand-alone model to verify the error in the combined model established in this study.

\section{Case analysis}

This study used a combination of forecasting models based on the ES method, the RA method, and the grey model methods to conduct forecasts on the logistic demands of the green tea industry of Nanjing using actual data on sales volumes and quantities of green tea in Nanjing from 2000 to 2018 . Specifically, the study analysis was divided into three stages. The first stage comprised the establishment of the ES model, the RA model, and the grey model. The second stage was establishing the combined forecasting model based on the TOPSIS modeling. The third stage was the establishment of the combined forecasting model and its forecasting results. The specific implementation steps of each stage follow, and the analysis flowchart is as presented in Figure 2.

This study used the case industry's sales data from 2000 to 2018 to represent the logistics demand data because of incomplete historical data, which conformed to the basic assumptions of the proposed model. Therefore, on the basis of the data on the sales quantities of green tea in Nanjing from 2000 to 2018, this study conducted the modeling and analysis for the forecasting models. The initial data of each year are as presented in Table 1. 


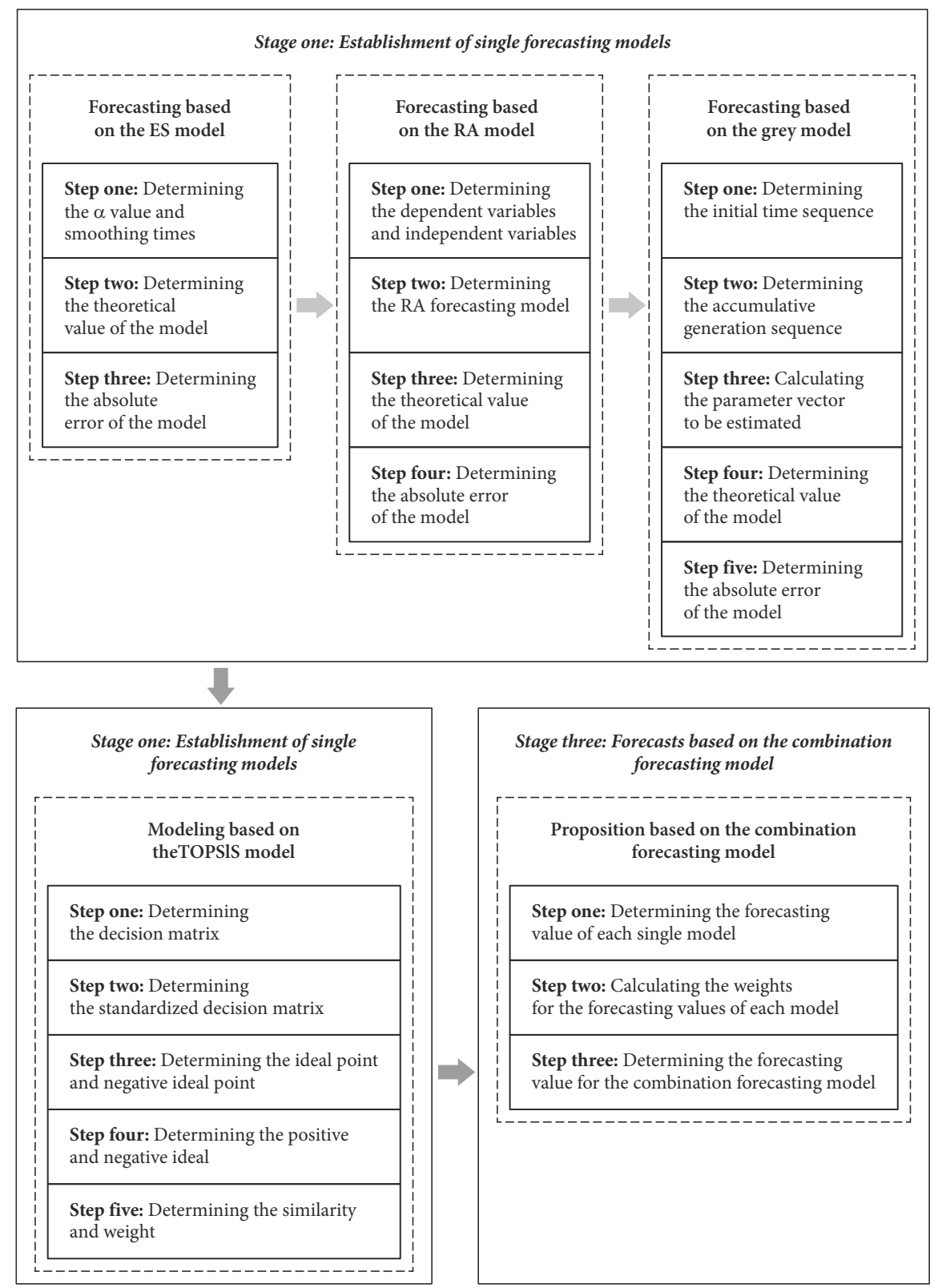

Figure 2. Analysis flowchart 
Table 1. Sales volume of green tea in Nanjing from 2000 to 2018

\begin{tabular}{|c|c|}
\hline Date (year) & Sales volume \\
\hline 2000 & 520 \\
\hline 2001 & 538 \\
\hline 2002 & 557 \\
\hline 2003 & 596 \\
\hline 2004 & 683 \\
\hline 2005 & 935 \\
\hline 2006 & 1028 \\
\hline 2007 & 1166 \\
\hline 2008 & 1258 \\
\hline 2009 & 1359 \\
\hline 2010 & 1475 \\
\hline 2011 & 1623 \\
\hline 2012 & 1790 \\
\hline 2013 & 1920 \\
\hline 2014 & 2080 \\
\hline 2015 & 2250 \\
\hline 2016 & 2780 \\
\hline 2017 & 2970 \\
\hline 2018 & 3060 \\
\hline
\end{tabular}

Note: Unit: metric ton.

\subsection{Analysis of single forecasting models}

\subsubsection{Forecasting based on the ES model}

Step 1: Determining the $\alpha$ value and smoothing times

The sales volume was set as the indicator of logistic demands in this study. The ES method was applied to analyze and forecast the logistic demand of the green tea industry, and the ES coefficient was determined based on the minimum sum of squares error and mean square error [9]. The ES calculation revealed that the conditions were met when; therefore, results in the optimal ES coefficient.

Step 2: Determining the theoretical value of the model

The ES forecasting value was obtained by computing Eqs. (A1) and (A2), and the results revealed that the basic ES model resulted in the minimum error, which means the forecast was more precise; therefore, the basic ES model was chosen for the forecast. The forecasting results obtained with the ES method based on the sales volume of green tea in Nanjing from 2000 to 2018 revealed a mean absolute error of 124.278 (Table 2). 
Table 2. Basic ES and double ES of the sales volume

\begin{tabular}{|c|c|c|c|c|c|c|c|c|}
\hline $\begin{array}{c}\text { Date } \\
\text { (year) }\end{array}$ & $\begin{array}{c}\text { Sales } \\
\text { volume } \\
\text { (metric } \\
\text { tons) }\end{array}$ & Basic ES & $\begin{array}{c}\text { Double } \\
\text { ES }\end{array}$ & $a_{t}$ & $b_{t}$ & $\begin{array}{c}\text { Forecasting } \\
\text { value }\end{array}$ & $\begin{array}{c}\text { Absolute } \\
\text { error } \\
\text { (basic ES) }\end{array}$ & $\begin{array}{c}\text { Absolute } \\
\text { error } \\
\text { (double ES) }\end{array}$ \\
\hline 2000 & 520 & 520.000 & 520.000 & & & & 0.000 & \\
\hline 2001 & 538 & 529.000 & 524.500 & 533.500 & 2.000 & & 9.000 & \\
\hline 2002 & 557 & 543.000 & 533.750 & 552.250 & 0.973 & 543.376 & 14.000 & 21.500 \\
\hline 2003 & 596 & 569.500 & 551.625 & 587.375 & 0.503 & 561.379 & 26.500 & 42.777 \\
\hline 2004 & 683 & 626.250 & 588.938 & 663.563 & 0.241 & 598.100 & 56.750 & 95.122 \\
\hline 2005 & 935 & 780.625 & 684.781 & 876.469 & 0.094 & 683.527 & 154.375 & 271.196 \\
\hline 2006 & 1028 & 904.313 & 794.547 & 1014.078 & 0.082 & 933.617 & 123.688 & 151.437 \\
\hline 2007 & 1166 & 1035.156 & 914.852 & 1155.461 & 0.075 & 1029.929 & 130.844 & 151.840 \\
\hline 2008 & 1258 & 1146.578 & 1030.715 & 1262.441 & 0.078 & 1166.424 & 111.422 & 102.464 \\
\hline 2009 & 1359 & 1252.789 & 1141.752 & 1363.826 & 0.081 & 1259.221 & 106.211 & 96.481 \\
\hline 2010 & 1475 & 1363.895 & 1252.823 & 1474.966 & 0.081 & 1359.800 & 111.105 & 111.093 \\
\hline 2011 & 1623 & 1493.447 & 1373.135 & 1613.759 & 0.075 & 1475.561 & 129.553 & 147.953 \\
\hline 2012 & 1790 & 1641.724 & 1507.429 & 1776.018 & 0.067 & 1623.221 & 148.276 & 176.166 \\
\hline 2013 & 1920 & 1780.862 & 1644.146 & 1917.578 & 0.066 & 1790.240 & 139.138 & 143.915 \\
\hline 2014 & 2080 & 1930.431 & 1787.288 & 2073.574 & 0.063 & 1920.916 & 149.569 & 162.356 \\
\hline 2015 & 2250 & 2090.215 & 1938.752 & 2241.679 & 0.059 & 2080.289 & 159.785 & 176.364 \\
\hline 2016 & 2780 & 2435.108 & 2186.930 & 2683.286 & 0.036 & 2250.334 & 344.892 & 538.262 \\
\hline 2017 & 2970 & 2702.554 & 2444.742 & 2960.366 & 0.035 & 2776.548 & 267.446 & 286.678 \\
\hline 2018 & 3060 & 2881.277 & 2663.009 & 3099.544 & 0.041 & 2973.007 & 178.723 & 99.599 \\
\hline & & & & & $M e a n$ & absolute error & 124.278 & 163.247 \\
\hline
\end{tabular}

Unit: metric ton.

\subsubsection{Forecasting based on the RA model}

Step 1: Determining dependent variables and arguments

Based on the assumption of time sequence RA model, this study represented the forecast volume of each year as the dependent variable $Y$ and the year in the time sequence as the argument $X$.

Step 2: Determining the RA forecasting model

The green tea sales volume and scattered points of time according to the time sequence (2000-2018) collected in this study were used to conduct a trend analysis. The scatter plot (Figure 3) reveals a gradual yearly increase, reflecting the theoretical assumption proposed by the exponential regression forecasting model. This model was therefore chosen for this study.

The exponential regression equation was obtained using Eqs (A5) and (A8). The calculation process follows.

Assuming the actual sales volume $Y$ and the year $X$ are exponentially correlated, the regression equation is as follows:

$$
Y=d c^{x}
$$




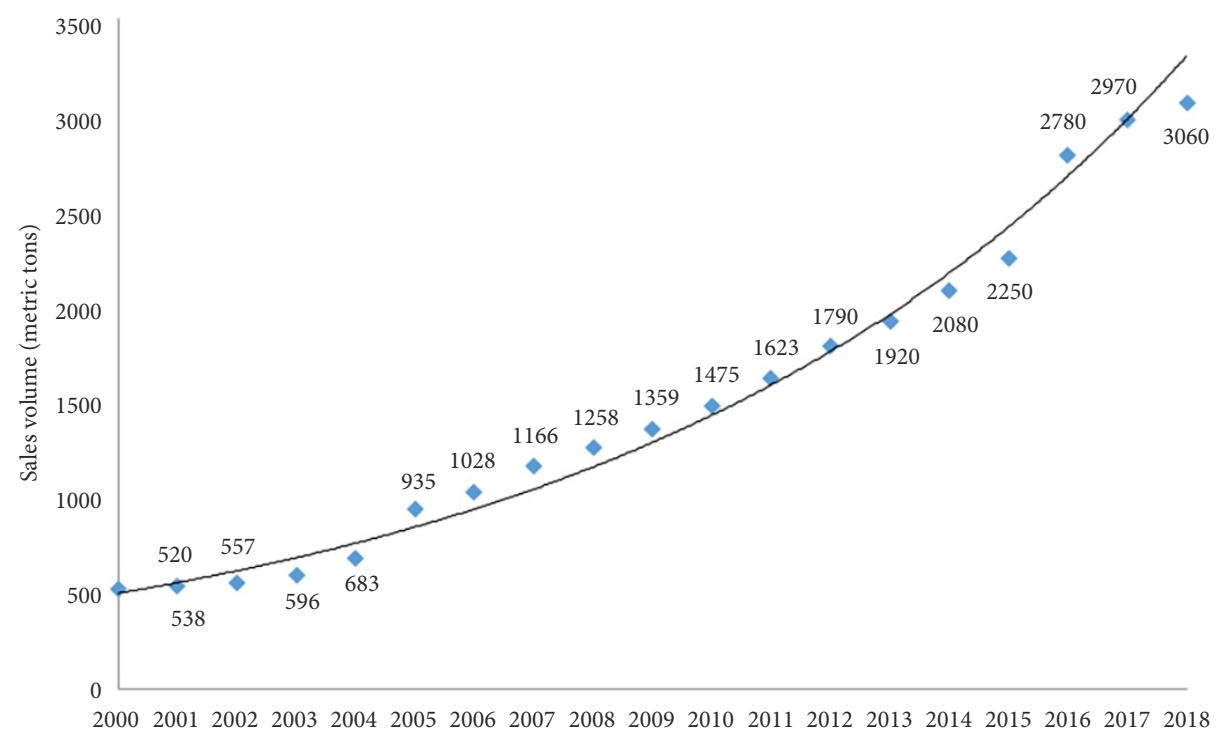

Figure 3. Sales volume changes over time

Applying logarithmic transformation on both sides results in the following equation:

$$
\log Y=\log d+X \log c .
$$

Make $Y=\log Y, b=\log c, a=\log d$.

The following equation is obtained:

$$
Y^{\prime}=a+b x .
$$

If the dependent variable, or the sales volume, $Y$ is affected only by the argument, or by time, $x$, the relationship and regression equation of $Y$ and $x$ is as follows:

$$
Y^{\prime}=\log Y=-88.286766+0.045542638 x
$$

that is,

$$
Y^{\prime}=\log Y=10^{-88.286766+0.045542638 x},
$$

where the correlation coefficient, which is highly correlated and therefore fits the assumptions of the theory.

Step 3: Determining the theoretical value of the model

The theoretical value of the model was calculated. The results are presented in Table 3.

Step 4: Determining the absolute error of the model

After the theoretic forecasting value of the model was determined in step three, Eq. (A4) was used to obtain the absolute error. The results were as presented in Table 3. 
Table 3. Forecasting value of the sales volume based on the RA model

\begin{tabular}{|c|c|c|c|}
\hline Year & Sales volume & Forecasting value & Absolute error \\
\hline 2000 & 520 & 500.274 & 19.726 \\
\hline 2001 & 538 & 555.585 & 17.585 \\
\hline 2002 & 557 & 617.012 & 60.012 \\
\hline 2003 & 596 & 685.229 & 89.229 \\
\hline 2004 & 683 & 760.989 & 77.989 \\
\hline 200 & 935 & 845.126 & 89.874 \\
\hline 2006 & 1028 & 938.564 & 89.436 \\
\hline 2007 & 1166 & 1042.333 & 123.667 \\
\hline 2008 & 1258 & 1157.575 & 100.425 \\
\hline 2009 & 1359 & 1285.558 & 73.442 \\
\hline 2010 & 1475 & 1427.692 & 47.308 \\
\hline 2011 & 1623 & 1585.540 & 37.460 \\
\hline 2012 & 1790 & 1760.839 & 29.161 \\
\hline 2013 & 1920 & 1955.520 & 35.520 \\
\hline 2014 & 2080 & 2171.726 & 91.726 \\
\hline 2015 & 2250 & 2411.835 & 161.835 \\
\hline 2016 & 2780 & 2678.492 & 101.508 \\
\hline 2017 & 2970 & 2974.630 & 4.630 \\
\hline 2018 & 3060 & 3303.509 & 243.509 \\
\hline \multicolumn{2}{|c|}{ Mean absolute error } & & 78.634 \\
\hline
\end{tabular}

Note: Unit: metric ton.

\subsubsection{Forecasting based on the Grey model}

The forecast for the logistic demand of the green tea industry was conducted using the grey model on the basis of the green tea sales volume in Nanjing from 2000 to 2018.

Step 1: Determining the initial time sequence

Based on the initial data sequence presented in Table 1, this study established an initial time sequence $X^{(0)}$ using Eq. (1). The initial time sequence from 2000 to 2018 was $X^{(0)}=$ $\{520,538,557,596,683,935,1028,1166,1258,1359,1475,1623,1790,1920,2080,2250$, $2780,2970,3060\}$.

Step 2: Determining the accumulative generation sequence

According to Eq. (2), the initial sequence was accumulated. The accumulative generation sequence for $2000-2018$ was $X(1)=\{520,1058,1615,2211,2894,3829,4857,6023,7281$, $8640,10115,11738,13528,15448,17528,19778,22558\}$. 
Step 3: Calculating the parameter vector to be estimated

The following results were obtained by calculating Eq. (3) to (4): $a=-0.092205777$ and $b=449.1241391$.

Step 4: Determining the theoretical value of the model

The theoretic forecasting value of 2000-2018 based on the grey model and Eq. (5) was as presented in Table 4.

Step 5: Determining the absolute error of the model

Once the theoretic forecasting value of the model was obtained in step three, Eq. (A4) was applied to obtain the absolute error. The results were as presented in Table 4.

Table 4. Forecasting value of the 2000-2018 sales volume based on the grey model

\begin{tabular}{|c|c|c|c|}
\hline Date (year) & Sales volume (metric tons) & Forecasting value & Absolute error \\
\hline 2000 & 520 & 520 & 0 \\
\hline 2001 & 538 & 603.888 & 65.888 \\
\hline 2002 & 557 & 665.704 & 108.704 \\
\hline 2003 & 596 & 733.848 & 137.848 \\
\hline 2004 & 683 & 808.968 & 125.968 \\
\hline 2005 & 935 & 891.777 & 43.223 \\
\hline 2006 & 1028 & 983.062 & 44.938 \\
\hline 2007 & 1166 & 1083.693 & 82.307 \\
\hline 2008 & 1258 & 1194.624 & 63.376 \\
\hline 2009 & 1359 & 1316.91 & 42.09 \\
\hline 2010 & 1475 & 1451.714 & 23.286 \\
\hline 2011 & 1623 & 1600.318 & 22.682 \\
\hline 2012 & 1790 & 1764.132 & 25.868 \\
\hline 2013 & 1920 & 1944.716 & 24.716 \\
\hline 2014 & 2080 & 2143.785 & 63.785 \\
\hline 2015 & 2250 & 2363.231 & 113.231 \\
\hline 2016 & 2780 & 2605.141 & 174.859 \\
\hline 2017 & 2970 & 2871.814 & 98.186 \\
\hline \multirow[t]{2}{*}{2018} & 3060 & 3165.784 & 105.784 \\
\hline & & Mean absolute error & 71.934 \\
\hline
\end{tabular}

Note: Unit: metric ton.

\subsection{Establishment based on the TOPSIS model}

According to the aforementioned calculations, the forecasts and absolute errors for each forecasting model were obtained, and these were used in this study to establish the combined forecasting model. The specific calculation process follows. 
Step 1: Determining the decision matrix

On the basis of the absolute error for each forecasting model, the decision matrix was established using Eq. (6). The decision matrix D of the ES model, the RA model, and the grey model, using 2000-2018 data, was as follows:

$D=\left[\begin{array}{ccc}9.000 & 17.585 & 65.888 \\ 14.000 & 60.012 & 108.704 \\ 26.500 & 89.229 & 137.848 \\ 56.750 & 77.989 & 125.968 \\ 154.375 & 89.874 & 43.223 \\ 123.688 & 89.436 & 44.938 \\ 130.844 & 123.667 & 82.307 \\ 111.422 & 100.425 & 63.376 \\ 106.211 & 73.442 & 42.090 \\ 111.105 & 47.308 & 23.286 \\ 129.553 & 37.460 & 22.682 \\ 148.276 & 29.161 & 25.868 \\ 139.138 & 35.520 & 24.716 \\ 149.569 & 91.726 & 63.785 \\ 159.785 & 161.835 & 113.231 \\ 344.892 & 101.508 & 174.859 \\ 267.446 & 4.630 & 98.186 \\ 178.723 & 243.509 & 105.784\end{array}\right]$.

Step 2: Determining the standardized decision matrix

According to the aforementioned decision matrix, Eq. (7) was applied to standardize the mean absolute error of each model. The standardized decision matrix $R$ of the ES model, the RA model, and the grey model, using 2000-2018 data, was as follows:

$$
R=\left[\begin{array}{lll}
0.131 & 0.256 & 0.958 \\
0.112 & 0.480 & 0.870 \\
0.159 & 0.536 & 0.829 \\
0.358 & 0.492 & 0.794 \\
0.840 & 0.489 & 0.235 \\
0.777 & 0.562 & 0.282 \\
0.661 & 0.625 & 0.416 \\
0.684 & 0.617 & 0.389 \\
0.782 & 0.541 & 0.310 \\
0.903 & 0.385 & 0.189 \\
0.947 & 0.274 & 0.166 \\
0.967 & 0.190 & 0.169 \\
0.955 & 0.244 & 0.170 \\
0.801 & 0.491 & 0.342 \\
0.629 & 0.637 & 0.446 \\
0.863 & 0.254 & 0.437 \\
0.939 & 0.016 & 0.345 \\
0.558 & 0.761 & 0.331
\end{array}\right] .
$$


Step 3: Determining the ideal point and negative ideal point

Calculating the standardized decision matrix using Eqs (8) and (9) to determine the ideal point and the negative ideal point.

Step 4: Determining the positive and negative ideal Euclidean distances

The ideal Euclidean distance and negative Euclidean distance were obtained using Eqs. (10) and (11). The results were as presented in Table 5 and Table 6.

Step 5: Determining the similarity and weight

The similarity and weight were obtained with Eqs (12) to (13). The results were as presented in Table 7.

Step 6: Determining the combined forecasting model

The equation for the combined forecasting model was established using Eqs (14) as

$$
Y=0.459 Y_{1}+0.237 Y_{2}+0.305 Y_{3} \text {, }
$$

where $Y$ is the forecasting value obtained from the combined forecasting model, $Y_{1}$ is the value obtained from the ES model, $Y_{2}$ is the value obtained from the exponential regression forecasting model, and $Y_{3}$ is the value obtained from the grey model.

Table 5. Ideal Euclidean distance

\begin{tabular}{|c|c|c|c|}
\hline Year & ES model & RA model & Grey model \\
\hline 2001 & 0.684 & 0.493 & 0.000 \\
\hline 2002 & 0.574 & 0.152 & 0.000 \\
\hline 2003 & 0.448 & 0.085 & 0.000 \\
\hline 2004 & 0.190 & 0.091 & 0.000 \\
\hline 2005 & 0.000 & 0.123 & 0.366 \\
\hline 2006 & 0.000 & 0.046 & 0.245 \\
\hline 2007 & 0.000 & 0.001 & 0.060 \\
\hline 2008 & 0.000 & 0.005 & 0.087 \\
\hline 2009 & 0.000 & 0.058 & 0.223 \\
\hline 2010 & 0.000 & 0.269 & 0.510 \\
\hline 2011 & 0.000 & 0.453 & 0.611 \\
\hline 2012 & 0.000 & 0.604 & 0.637 \\
\hline 2013 & 0.000 & 0.506 & 0.617 \\
\hline 2014 & 0.000 & 0.096 & 0.211 \\
\hline 2015 & 0.000 & 0.000 & 0.037 \\
\hline 2016 & 0.000 & 0.371 & 0.181 \\
\hline 2017 & 0.000 & 0.851 & 0.353 \\
\hline 2018 & 0.041 & 0.000 & 0.185 \\
\hline
\end{tabular}


Table 6. Negative ideal Euclidean distance

\begin{tabular}{|c|c|c|c|}
\hline Year & ES model & Exponential regression model & Grey model \\
\hline 2001 & 0.000 & 0.016 & 0.684 \\
\hline 2002 & 0.000 & 0.136 & 0.574 \\
\hline 2003 & 0.000 & 0.142 & 0.448 \\
\hline 2004 & 0.000 & 0.018 & 0.190 \\
\hline 2005 & 0.366 & 0.064 & 0.000 \\
\hline 2006 & 0.245 & 0.078 & 0.000 \\
\hline 2007 & 0.060 & 0.044 & 0.000 \\
\hline 2008 & 0.087 & 0.052 & 0.000 \\
\hline 2009 & 0.223 & 0.053 & 0.000 \\
\hline 2010 & 0.510 & 0.038 & 0.000 \\
\hline 2011 & 0.611 & 0.012 & 0.000 \\
\hline 2012 & 0.637 & 0.000 & 0.000 \\
\hline 2013 & 0.617 & 0.005 & 0.000 \\
\hline 2014 & 0.211 & 0.022 & 0.000 \\
\hline 2015 & 0.034 & 0.037 & 0.000 \\
\hline 2016 & 0.371 & 0.000 & 0.034 \\
\hline 2017 & 0.851 & 0.000 & 0.108 \\
\hline 2018 & 0.052 & 0.185 & 0.000 \\
\hline
\end{tabular}

Table 7. Similarities and weights

\begin{tabular}{|l|c|c|c|c|}
\hline & $\begin{array}{c}\text { Ideal Euclidean } \\
\text { distance }\end{array}$ & $\begin{array}{c}\text { Negative ideal } \\
\text { Euclidean distance }\end{array}$ & Similarity & Weight \\
\hline ES model & 1.392 & 2.208 & 0.613 & 0.459 \\
\hline Exponential regression model & 2.051 & 0.950 & 0.317 & 0.237 \\
\hline Grey model & 2.079 & 1.428 & 0.407 & 0.305 \\
\hline
\end{tabular}

Step 7: Error verification for the combined forecasting model

Eq. (15) was used in this study to obtain the theoretic value of the logistic demand of the green tea industry from 2000 to 2018 using the combined forecasting model. Said value was compared with the value for each forecasting model to verify the error from the combined forecasting model. The analysis results from Figure 4 and Table 8 revealed that the ES model was more accurate in the early period, the RA model was more accurate for the middle period, and the grey model was more accurate for the mid-late period. To enhance the overall accuracy of the forecast, the TOPSIS model was applied to determine the weight of each forecasting model on the basis of each model's absolute error. The weights were included in the calculation to determine the forecasting value for the combined forecasting model. The results indicated that the error for the combined forecasting model was lower than for any of the single forecasting models, which proved the applicability of the combined forecasting model. 


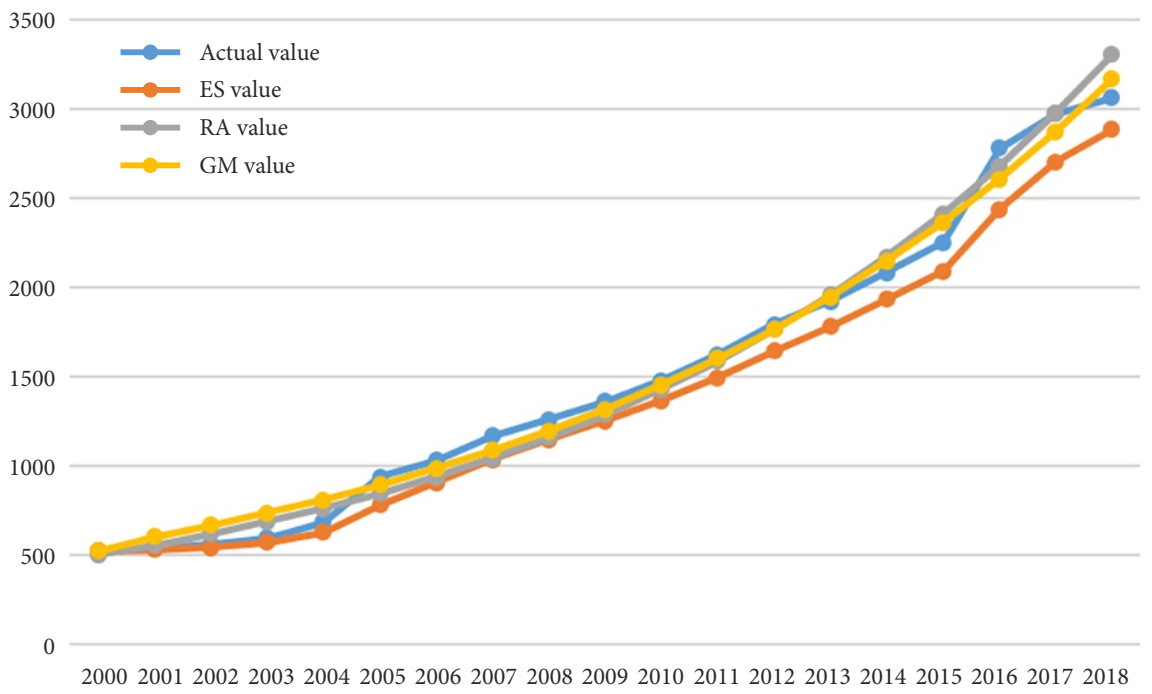

Figure 4. Comparison of the forecasting values for three models and the actual values

Table 8. Forecasting value of the logistic demand of the green tea industry from 2000 to 2018

\begin{tabular}{|c|c|c|c|c|c|c|c|c|c|}
\hline Year & $\begin{array}{c}\text { Actual } \\
\text { value }\end{array}$ & $\begin{array}{c}\text { ES } \\
\text { value }\end{array}$ & $\begin{array}{c}\text { Error } \\
(\%)\end{array}$ & RA value & $\begin{array}{c}\text { Error } \\
(\%)\end{array}$ & GM value & $\begin{array}{c}\text { Error } \\
(\%)\end{array}$ & $\begin{array}{c}\text { Combined } \\
\text { model value }\end{array}$ & $\begin{array}{c}\text { Error } \\
(\%)\end{array}$ \\
\hline 2001 & 538 & 529.000 & 1.67 & 555.585 & 3.27 & 603.888 & 12.25 & 558.670 & 3.84 \\
\hline 2002 & 557 & 543.000 & 2.51 & 617.012 & 10.77 & 665.704 & 19.52 & 598.508 & 7.45 \\
\hline 2003 & 596 & 569.500 & 4.45 & 685.229 & 14.97 & 733.848 & 23.13 & 647.623 & 8.66 \\
\hline 2004 & 683 & 626.250 & 8.31 & 760.989 & 11.42 & 808.968 & 18.44 & 714.538 & 4.62 \\
\hline 2005 & 935 & 780.625 & 16.51 & 845.126 & 9.61 & 891.777 & 4.62 & 830.594 & 11.17 \\
\hline 2006 & 1028 & 904.313 & 12.03 & 938.564 & 8.70 & 983.062 & 4.37 & 937.353 & 8.82 \\
\hline 2007 & 1166 & 1035.156 & 11.22 & 1042.333 & 10.61 & 1083.693 & 7.06 & 1052.696 & 9.72 \\
\hline 2008 & 1258 & 1146.578 & 8.86 & 1157.575 & 7.98 & 1194.624 & 5.04 & 1164.985 & 7.39 \\
\hline 2009 & 1359 & 1252.789 & 7.82 & 1285.558 & 5.40 & 1316.910 & 3.10 & 1281.365 & 5.71 \\
\hline 2010 & 1475 & 1363.895 & 7.53 & 1427.692 & 3.21 & 1451.714 & 1.58 & 1407.163 & 4.60 \\
\hline 2011 & 1623 & 1493.447 & 7.98 & 1585.540 & 2.31 & 1600.318 & 1.40 & 1549.362 & 4.54 \\
\hline 2012 & 1790 & 1641.724 & 8.28 & 1760.839 & 1.63 & 1764.132 & 1.45 & 1708.930 & 4.53 \\
\hline 2013 & 1920 & 1780.862 & 7.25 & 1955.520 & 1.85 & 1944.716 & 1.29 & 1874.012 & 2.40 \\
\hline 2014 & 2080 & 1930.431 & 7.19 & 2171.726 & 4.41 & 2143.785 & 3.07 & 2054.621 & 1.22 \\
\hline 2015 & 2250 & 2090.215 & 7.10 & 2411.835 & 7.19 & 2363.231 & 5.03 & 2251.799 & 0.08 \\
\hline 2016 & 2780 & 2435.108 & 12.41 & 2678.492 & 3.65 & 2605.141 & 6.29 & 2547.085 & 8.38 \\
\hline 2017 & 2970 & 2702.554 & 9.00 & 2974.630 & 0.16 & 2871.814 & 3.31 & 2821.363 & 5.00 \\
\hline 2018 & 3060 & 2881.277 & 5.84 & 3303.509 & 7.96 & 3165.784 & 3.46 & 3071.002 & 0.36 \\
\hline
\end{tabular}

Note: Unit: metric ton. 


\subsection{Forecasts for the combined forecasting model}

Step 1: Determining the forecasting value of each stand-alone model

According to the time sequence of 2000-2018, this study conducted forecasts on the logistic demands of the green tea industry over the next 10 years using various forecasting models. The forecasting results were as presented in Table 9.

Step 2: Calculating the weights for the forecasting values of each model

Eq. (15) was applied to obtain the weight for each model. The results were as presented in Table 9.

Step 3: Determining the forecasting value for the combined forecasting model. Consequently, Eq. (15) was used to forecast the logistic demands of the green tea industry over the next 10 years. The results were as presented in Table 9.

Table 9. Forecasting value of the logistic demand of the green tea industry from 2019 to 2028

\begin{tabular}{|c|c|c|c|c|}
\hline Year & ES value & RA value & GM value & Combined model value \\
\hline 2019 & 2990.431 & 3668.751 & 3489.846 & 3306.505 \\
\hline 2020 & 3072.314 & 4074.373 & 3847.081 & 3549.178 \\
\hline 2021 & 3133.749 & 4524.843 & 4240.883 & 3804.248 \\
\hline 2022 & 3179.856 & 5025.116 & 4674.997 & 4076.381 \\
\hline 2023 & 3214.477 & 5580.701 & 5153.548 & 4369.903 \\
\hline 2024 & 3240.497 & 6197.712 & 5681.086 & 4688.977 \\
\hline 2025 & 3260.084 & 6882.941 & 6262.624 & 5037.736 \\
\hline 2026 & 3274.870 & 7643.929 & 6903.691 & 5420.403 \\
\hline 2027 & 3286.087 & 8489.054 & 7610.381 & 5841.386 \\
\hline 2028 & 3294.669 & 9427.617 & 8389.409 & 6305.368 \\
\hline
\end{tabular}

Note: Unit: metric ton.

\section{Conclusions}

The ES model, RA model, and grey model used in this study are commonly used methods for forecasting logistic volume. Each model is relatively accurate within a particular time period and has larger error in other time periods, according to the complete dataset. Therefore, this study established a combined forecasting model based on these three forecasting methods and actual data on green tea sales volumes in Nanjing from 2000 to 2018 to conduct forecasts of the logistic demand of Nanjing's green tea industry. The aim of the model established in this study was to reduce errors and increase the accuracy and integrity of the forecast to properly forecast the changing trends of the logistic demands.

The logistic demand of the green tea industry in Nanjing in the next 10 years is gradually increasing by the years. As the logistic demand increases, green tea production must increase correspondingly. However, the facilities of the green tea production bases in the countryside of Nanjing are outdated and the logistic infrastructures incomplete, which renders tea planta- 
tion sites unable to respond appropriately to the rapid development of the green tea industry and its high logistic demands.

Therefore, this study proposed the following suggestions based on the results obtained in the research:

\section{(1) Regarding logistic constructions}

The government must establish a comprehensive logistic plan for the countryside. In addition, corresponding supplementary policies must be established and logistic infrastructures improved to attract investment from companies of green tea production of logistic services to ensure that the logistic capacity of green tea production bases in the countryside can meet rapidly growing green tea logistic demands. Middle to large-scale green tea production companies must comply with economic policies that aim to attract investment in the countryside and implement construction plans in collaboration with green tea production bases in the countryside. Proper logistic demand forecasting data may mitigate unnecessary losses for tea farmers and increase profits for tea companies, which signifies a win-win collaboration.

\section{(2) Regarding market conditions}

Because of Nanjing's advantageous location and large market, green tea companies there must respond to the production bases and consumer markets within the city as well as consumers elsewhere and even in foreign markets. Therefore, optimizing accuracy in green tea demand forecasting is critical. The government must establish a specialized technical division to conduct green tea demand forecasts for facilitating immediate adjustments of relevant economic policies to impede market turmoil due to underproduction or overproduction. Green tea companies shall follow this lead to mitigate economic losses caused by problems such as insufficient green tea stocks, price reductions caused by overstocking, or increased storage costs.

\section{Acknowledgements}

The authors gratefully acknowledge the financial supports by the Sanming University [grant number 19YG06S].

\section{References}

Baffour, A. A., Feng, J., \& Taylor, E. K. (2019). A hybrid artificial neural network-GJR modeling approach to forecasting currency exchange rate volatility. Neurocomputing, 365, 285-301. https://doi.org/10.1016/j.neucom.2019.07.088

Baginski, S. P., \& Hassell, J. M. (1997). Determinants of management forecast precision. The Accounting Review, 72(2), 303-312.

Bai, C., \& Sarkis, J. (2018). Integrating sustainability into supplier selection: a grey-based TOPSIS analysis. Technological and Economic Development of Economy, 24(6), 2202-2224. https://doi.org/10.3846/tede.2018.5582

Bates, J. M., \& Granger, C. W. J. (1969). The combination of forecasts. Journal of the Operational Research Society, 20(4), 451-468. https://doi.org/10.1057/jors.1969.103 
Carmona-Benítez, R. B., \& Nieto, M. R. (2020). SARIMA damp trend grey forecasting model for airline industry. Journal of Air Transport Management, 82, 101736.

https://doi.org/10.1016/j.jairtraman.2019.101736

Chang, S. C., Lai, H. C., \& Yu, H. C. (2005). A variable P value rolling Grey forecasting model for Taiwan semiconductor industry production. Technological Forecasting and Social Change, 72, 623-640. https://doi.org/10.1016/j.techfore.2003.09.002

Chao, T., \& Peng, J. (2020). An integrated picture fuzzy ANP-TODIM multi-criteria decision-making approach for tourism attraction recommendation. Technological and Economic Development of Economy, 26(2), 331-354. https://doi.org/10.3846/tede.2019.11412

Colino, E. V., Irwin, S. H., Garcia, P., \& Etienne, X. (2012). Composite and outlook forecast accuracy. Journal of Agricultural and Resource Economics, 37(2), 228-246.

Deng, J. (1982). Control problems of grey systems. Systems \& Control Letters, 1(5), 288-294. https://doi.org/10.1016/S0167-6911(82)80025-X

Fernández-Vázquez, E., \& Moreno, B. (2017). Entropy econometrics for combining regional economic forecasts: A data-weighted prior estimator. Journal of Geographical Systems, 19(4), 349-370. https://doi.org/10.1007/s10109-017-0259-9

Gao, Y., Chang, D., Fang, T., \& Luo, T. (2018). The correlation between logistics industry and other industries: an evaluation of the empirical evidence from china. The Asian Journal of Shipping and Logistics, 34(1), 27-32. https://doi.org/10.1016/j.ajsl.2018.03.004

Ghosh, I., Jana, R. K., \& Sanyal, M. K. (2019). Analysis of temporal pattern, causal interaction and predictive modeling of financial markets using nonlinear dynamics, econometric models and machine learning algorithms. Applied Soft Computing, 82, 105553. https://doi.org/10.1016/j.asoc.2019.105553

Glosten, L. R., Jagannathan, R., \& Runkle, D. E. (1993). On the relation between the expected value and the volatility of the nominal excess return on stocks. Journal of Finance, 48(5), 1779-1801. https://doi.org/10.1111/j.1540-6261.1993.tb05128.x

Guo, Y., Yao, S., Cheng, H., \& Zhu, W. (2020). China's copper futures market efficiency analysis: based on nonlinear granger causality and multifractal methods. Resources Policy, 68, 101716. https://doi.org/10.1016/j.resourpol.2020.101716

Hilary, L. S. (1967). The historical development of the Gauss linear model. Biometrika, 54 (1/2), 1-24. https://doi.org/10.1093/biomet/54.1-2.1

Hsu, C. C., \& Chen, C. Y. (2003). Applications of improved grey prediction model for power demand forecasting. Energy Conversion and Management, 44, 2241-2249. https://doi.org/10.1016/S0196-8904(02)00248-0

Hsu, L. C. (2003). Apply the grey prediction model to the global integrated circuit industry. Technological Forecasting and Social Change, 70(6), 563-574. https://doi.org/10.1016/S0040-1625(02)00195-6

$\mathrm{Hu}$, Y. C. (2020). Constructing grey prediction models using grey relational analysis and neural networks for magnesium material demand forecasting. Applied Soft Computing, 93, 106398. https://doi.org/10.1016/j.asoc.2020.106398

Hwang, C., \& Yoon, K. (1981). Multiple attribute decision making: Methods and application. Springer Publications. https://doi.org/10.1007/978-3-642-48318-9

Ji, S. W., Li, T. K., Chen, G. P., Su, G., \& Zhang, Q. C. (2015). Ann forecast algorithmic model for port logistic demand research. Applied Mechanics and Materials, 744-746, 1869-1872. https://doi.org/10.4028/www.scientific.net/AMM.744-746.1869

Jia, Z. Q., Zhou, Z. F., Zhang, H. J., Li, B., \& Zhang, Y. X. (2020). Forecast of coal consumption in Gansu Province based on Grey-Markov chain model. Energy, 199, 117444.

https://doi.org/10.1016/j.energy.2020.117444 
Jiani, W., \& Hans-Dietrich, H. (2018). The freight village as a pathway to sustainable agricultural products logistics in china. Journal of Cleaner Production, 196, 1227-1238.

https://doi.org/10.1016/j.jclepro.2018.06.077

Lamsal, K., Jones, P. C., \& Thomas, B. W. (2016). Harvest logistics in agricultural systems with multiple, independent producers and no on-farm storage. Computers \& Industrial Engineering, 91, 129-138. https://doi.org/10.1016/j.cie.2015.10.018

Lin, H. L., \& Cho, C. C. (2020). An ideal model for a merger and acquisition strategy in the information technology industry a case study for investment in the Taiwanese industrial personal computer sector. Journal of Testing and Evaluation, 48(2), 775-793. https://doi.org/10.1520/JTE20170106

Lin, H. L., Cho, C. C., Ma, Y. Y., Hu, Y.-Q., \& Yang, G. H. (2019). Optimization plan for excess warehouse storage in e-commerce based plant shops: a case study for Chinese plant industrial. Journal of Business Economics and Management, 20(4), 776-798. https://doi.org/10.3846/jbem.2019.10188

Liu, L., Wang, H., \& Xing, S. H. (2019). Optimization of distribution planning for agricultural products in logistics based on degree of maturity. Computers and Electronics in Agriculture, 160, 1-7. https://doi.org/10.1016/j.compag.2019.02.030

Mahmoudi, A., Javed, S. A., Liu, S., \& Deng, X. (2020). Model for intelligent decisions: application in project management. Technological and Economic Development of Economy, 26(3), 621-641. https://doi.org/10.3846/tede.2020.11890

National Bureau of Statistics of China. (2018). China statistical information service. http://www.stats.gov.cn/

Wang, Q., Li, S., Li, R., \& Ma, M. (2018). Forecasting U.S. shale gas monthly production using a hybrid ARIMA and metabolic nonlinear grey model. Energy, 160, 378-387. https://doi.org/10.1016/j.energy.2018.07.047

Wu, W., Ma, X., Zeng, B., Wang, Y., \& Cai, W. (2019). Forecasting short-term renewable energy consumption of China using a novel fractional nonlinear grey Bernoulli model. Renewable Energy, 140, 70-87. https://doi.org/10.1016/j.renene.2019.03.006

Xu, Q., Wang, L., Jiang C., \& Zhang, X. (2019). A novel UMIDAS-SVQR model with mixed frequency investor sentiment for predicting stock market volatility. Expert Systems with Applications, 132, 12-27. https://doi.org/10.1016/j.eswa.2019.04.066

Zainuddin, N. H., Lola, M. S., Djauhari, M. A., Yusof, F., Afiq Ramlee, M. N., Deraman, A., Ibrahim, Y., \& Abdullah, M. T. (2019). Improvement of time forecasting models using a novel hybridization of bootstrap and double bootstrap artificial neural networks. Applied Soft Computing, 84, 105676. https://doi.org/10.1016/j.asoc.2019.105676

Zemlickiene, V., \& Turskis, Z. (2020). Evaluation of the expediency of technology commercialization: a case of information technology and biotechnology. Technological and Economic Development of Economy, 26(1), 271-289. https://doi.org/10.3846/tede.2020.11918

Zhang, C., Huang, L., \& Zhao, Z. (2013). Research on combination forecast of port cargo throughput based on time series and causality analysis. Journal of Industrial Engineering and Management, 6(1), 124-134. https://doi.org/10.3926/jiem.687

Zhuang, Z. Y., Su, C. R., \& Chang, S. C. (2019). The effectiveness f IF-MADM (Intuitionistic-fuzzy multi attribute decision-making) for group decisions: methods and an empirical assessment for the selection of a senior centre. Technological and Economic Development of Economy, 25(2), 322-364. https://doi.org/10.3846/tede.2019.8399

Zill, D. G., \& Cullen, M. R. (2000). Advance Engineering Mathematics. Jones and Barhett. 


\section{APPENDIX}

\section{ES model}

ES times calculation model, the equation is as follows (Lin et al., 2019):

$$
\begin{gathered}
S_{t}^{(1)}=\alpha y_{t}+(1-\alpha) S_{t-1}^{(1)} ; \\
S_{t}^{(2)}=\alpha S_{t}^{(1)}+(1-\alpha) S_{t-1}^{(2)} ; \\
S_{t}^{(3)}=\alpha S_{t}^{(2)}+(1-\alpha) S_{t-1}^{(3)},
\end{gathered}
$$

where $Y_{i}$ is the initial value, which refers to the initial data of the logistic demand; $\alpha$ is the ES coefficient; $t$ is the smooth time sequence; and $S_{t}^{(1)}, S_{t}^{(2)}, S_{t}^{(3)}$ are the basic, double, and triple ES value of time $t$, respectively.

The difference between the theoretical value and the actual value was subsequently used to obtain the absolute error. The equation is as follows:

$$
(E)=\left|X_{t}-F_{t}\right|,
$$

where $(E)$ is the absolute error, $X_{t}$ is the actual value, and $F_{t}$ is the measured value.

\section{RA model}

For scattered points forming a straight line, the basic model is as follows (Hilary, 1967):

$$
Y=a+b x .
$$

For scattered points forming a curved line, the forecast may be obtained using the logarithm model, quadratic model, cubic model, or exponential model. The basic model is as follows:

The logarithm model:

$$
Y=a+b \ln x .
$$

The quadratic model:

$$
Y=a+b x+c x^{2} .
$$

The cubic model:

$$
Y=a+b x+c x^{2}+d x^{3}
$$

The exponential model:

$$
Y=d c^{x} .
$$

